\title{
A quantitative proteomics study on olfactomedin 4 in the development of gastric cancer
}

\author{
XIAOPING RAN ${ }^{1 *}$, XIAOMING XU $^{1 *}$, YIXUAN YANG ${ }^{1-3}$, SHA SHE $^{1}$, MIN YANG $^{1}$, \\ SHIYING LI ${ }^{1}$, HONG PENG ${ }^{1}$, XIANGCHUN DING ${ }^{4}$, HUAIDONG HU ${ }^{1-3}$, PENG HU $^{1-3}$, \\ DAZHI ZHANG ${ }^{1-3}$, HONG REN ${ }^{1-3}$, LIGANG WU $^{5}$ and WEIQUN ZENG ${ }^{1-3}$
}

\begin{abstract}
${ }^{1}$ Department of Infectious Diseases, The Second Affiliated Hospital of Chongqing Medical University, Chongqing 400010; ${ }^{2}$ Institute for Viral Hepatitis of Chongqing Medical University, Chongqing 400016; ${ }^{3}$ Key Laboratory of Molecular Biology for Infectious Diseases, Ministry of Education, Chongqing Medical University, Chongqing 400016; ${ }^{4}$ Department of Infectious Diseases, General Hospital of Ningxia Medical University, Yinchuan, Ningxia 750004; ${ }^{5}$ Department of Oncological Surgery, General Hospital of Ningxia Medical University, Yinchuan, Ningxia 750004, P.R. China
\end{abstract}

Received June 27, 2015; Accepted August 7, 2015

DOI: $10.3892 /$ ijo.2015.3168

\begin{abstract}
Gastric cancer (GC) is now one of the most common malignancies with a relatively high incidence and high mortality rate. The prognosis is closely related to the degree of tumor metastasis. The mechanism of metastasis is still unclear. Proteomics analysis is a powerful tool to study and evaluate protein expression in tumor tissues. In the present study, we collected 15 gastric cancer and adjacent normal gastric tissues and used the isobaric tags for relative and absolute quantitation (iTRAQ) method to identify differentially expressed proteins. A total of 134 proteins were differentially expressed between the cancerous and non-cancerous samples. Azurocidin 1 (AZU1), CPVL, olfactomedin 4 (OLFM4) and Villin 1 (VIL1) were upregulated and confirmed by western blot analysis, real-time quantitative PCR and immunohistochemical analyses. These results were in accordance with iTRAQ. Furthermore, silencing the OLFM4 expression suppressed the migration, invasion and proliferation of the GC cells in vitro. The present study represents a successful application of the iTRAQ method in analyzing the expression levels of thousands of proteins. Overexpression of OLFM4 in gastric cancer may
\end{abstract}

Correspondence to: Dr Ligang Wu, Department of Oncological Surgery, General Hospital of Ningxia Medical University, Yinchuan, Ningxia 750004, P.R. China

E-mail: wuligang654321@163.com

Dr Weiqun Zeng, Department of Infectious Diseases, The Second Affiliated Hospital of Chongqing Medical University, No. 74 Lin Jiang Road, Yuzhong, Chongqing 400010, P.R. China

E-mail: zwq641213@sina.com

${ }^{*}$ Contributed equally

Key words: gastric cancer, mechanism, olfactomedin 4, iTRAQ, migration, invasion, proteomics induce the development of gastric cancer. Overall, suppression of OLFM4 expression may be a promising strategy in the development of novel cancer therapeutic drugs.

\section{Introduction}

Gastric cancer (GC) is the fifth most common cancer in the world, following lung, breast, prostate and colorectal cancers, with an estimated 952,000 newly reported cases and 723,000 related deaths in 2012. Of these new cases, more than $70 \%$ occurred in less developed regions, with $50 \%$ occurring in Eastern Asia (mainly in China) (1). The depth of wall invasion, local lymph node and distal organ invasion, which are found with tumor-metastasis in the clinical staging systems, are evaluated for GC diagnosis and prognosis. A 5-year survival rate of $>90 \%$ has been observed for patients diagnosed with early gastric cancer, whereas the survival rate is only $5 \%$ for those diagnosed with GC with synchronous distant metastasis (2). The mechanism of metastasis is still unknown. Therefore, investigating the molecular mechanism of gastric cancer metastasis could provide insights to improve diagnosis and therapeutic approaches.

In recent years, proteomics analysis has provided us with a powerful, global tool to study and evaluate protein expression. Two-dimensional gel electrophoresis (2-DE) was widely used in proteomics-based approaches, which has been traditionally performed in order to identify the cancer-related protein (3). However, 2-DE is a labor-intensive method which is insensitive to the detection of low-abundance protein and hydrophobic membrane proteins. Both limited sample capacity and low linear visualization range are its disadvantages (4). Nowadays, isotope-based quantitative proteomics is widely used in the identification and quantification of proteins, such as isobaric tags for relative and absolute quantitation (iTRAQ) (5), ICAT (6), $18 \mathrm{O}$ (7) and SILAC (8). Among these techniques, the iTRAQ method is an MS/MS-based technique which enables both protein identification and relative quantification in a multiplexed experiment. 
Table I. The clinical and pathological data of gastric cancer patients (15 samples).

\begin{tabular}{llclccccc}
\hline Sample no. & Gender & Age (years) & Tumor position & Pathology & Grade & Stage & TNM & Type \\
\hline 1 & Female & 68 & Gastric antrum & Adenocarcinoma & 3 & IIIb & T4N2M0 & Malignant \\
2 & Male & 59 & Gastric antrum & Adenocarcinoma & 3 & IIIa & T2N3M0 & Malignant \\
3 & Female & 65 & Gastric fundus & Adenocarcinoma & 3 & II & T2N1M0 & Malignant \\
4 & Male & 65 & Gastric body & Adenocarcinoma & 3 & IIIa & T4N1M0 & Malignant \\
5 & Male & 60 & Gastric antrum & Adenocarcinoma & 3 & IIIb & T3N3M0 & Malignant \\
6 & Female & 73 & Gastric antrum & Adenocarcinoma & 3 & IV & T3N2M1 & Malignant \\
7 & Male & 47 & Gastric antrum & Adenocarcinoma & 3 & IIIa & T2N3M0 & Malignant \\
8 & Female & 67 & Gastric body & Adenocarcinoma & 3 & IV & T3N3M1 & Malignant \\
9 & Male & 77 & Gastric fundus & Adenocarcinoma & 3 & IV & T3N0M1 & Malignant \\
10 & Female & 51 & Gastric antrum & Adenocarcinoma & 3 & IIIa & T3N2M0 & Malignant \\
11 & Male & 55 & Gastric antrum & Adenocarcinoma & 3 & IV & T2N3M1 & Malignant \\
12 & Male & 78 & Gastric body & Adenocarcinoma & 3 & IV & T3N3M1 & Malignant \\
13 & Female & 56 & Gastric antrum & Adenocarcinoma & 3 & IIIa & T3N2M0 & Malignant \\
14 & Male & 64 & Gastric antrum & Adenocarcinoma & 2 & II & T2N1M0 & Malignant \\
15 & Female & 65 & Gastric fundus & Adenocarcinoma & 2 & II & T1N2M0 & Malignant \\
\hline
\end{tabular}

In the present study, we used the quantitation of the proteomics method to analyze the differences of protein expression levels between gastric cancer and normal gastric tissues. Among these proteins, we focused on olfactomedin 4 (OLFM4) because this protein has recently been shown to be aberrantly expressed in malignancies. Furthermore, the study on the function of OLFM4 in gastric cancer had not been previously reported. We further studied the biological function of GC cells silencing OLFM4 expression, in an attempt to determine whether the overexpression of this protein is relevant to the malignancy of gastric cancer.

\section{Materials and methods}

Patients and cell lines. Fifteen patients with gastric cancer were included in this study (Table I). In our clinical patients, a majority of GC patients had neoplasms of intermediate differentiation (stage III or IV). The patients were selected from gastric cancer patients from the Second Affiliated Hospital of Chongqing Medical University. Gastric cancer tissues and adjacent non-cancer gastric tissue were used for iTRAQ-coupled LC-MS/MS analyses. Non-cancer tissues were obtained from the distal edge of the resection at least $10 \mathrm{~cm}$ from the tumor. The study was approved by the Ethics Committee of Chongqing Medical University and all patients signed written informed consent prior to participation in the present study. Two human gastric cancer cell lines (AGS and MKN28) from ATCC were grown in RPMI-1640 medium supplanted with $10 \%$ fetal bovine serum (FBS; Gibco, San Diego, CA, USA) and penicillin and incubated in an atmosphere of $5.0 \%$ carbon dioxide at $37^{\circ} \mathrm{C}$.

Protein digestion and peptide iTRAQ labeling. The 8-plex iTRAQ kits were obtained from Applied Biosystems (Foster City, CA, USA). All the proteins were extracted using a Sample Grinding kit obtained from Amersham Biosciences with lysis buffer which contains $7 \mathrm{M}$ urea, $1 \mathrm{mM}$ PMSF, $1 \mathrm{mM} \mathrm{Na} \mathrm{VO}_{4}$ and $1 \mathrm{mg} / \mathrm{ml}$ DNase I. After being centrifuged at $15,000 \mathrm{rpm}$ for $15 \mathrm{~min}$ at $4^{\circ} \mathrm{C}(9)$, the supernatant liquid was collected, then the protein concentrations were quantified by the 2D Quantification kit. Approximately $100 \mu \mathrm{g}$ of protein from each sample were further precipitated with ice-cold acetone at $-20^{\circ} \mathrm{C}$ overnight and dissolved with a denatured lysis buffer. According to the manufacturer's instrument (Applied Biosystems, Framingham, MA, USA), the cysteines were then blocked. Each sample was digested to peptides using $20 \mu \mathrm{l}$ of $0.1 \mu \mathrm{g} / \mu \mathrm{l}$ sequencing grade modified trypsin (Promega) solution at $37^{\circ} \mathrm{C}$ overnight. Labeling was as follows with different isobaric tags: i) gastric cancer tissues, 117 and 119 tags; and ii) normal gastric tissues, 118 and 121 tags. Prior to fractionation of peptides, the labeled samples were placed at room temperature for $1 \mathrm{~h}$ and combined.

Peptide fractionation. The pooled iTRAQ-labeled samples were solubilized in $300 \mu \mathrm{l}$ of $1 \%$ Pharmalyte (Amersham Biosciences) and $8 \mathrm{M}$ urea. Samples were used to rehydrate 18 cm-long IPG gel strips (pH 3-10; Amersham Biosciences) at $30 \mathrm{~V}$ for $14 \mathrm{~h}$. Electrofocusing of the peptides was carried out successively at $500 \mathrm{~V}$ for $1 \mathrm{~h}, 1000 \mathrm{~V}$ for $1 \mathrm{~h}, 3000 \mathrm{~V}$ for $1 \mathrm{~h}$ and $8000 \mathrm{~V}$ for $8.5 \mathrm{~h}$ to reach a final level of $68 \mathrm{kV} \bullet \mathrm{h}$. After focusing, the strips were withdrawn and sliced into 36 sections of $5 \mathrm{~mm}$ thickness. Peptides were extracted by incubating the gel pieces in $100 \mu \mathrm{l}$ of $2 \%$ acetonitrile, $0.1 \%$ formic acid for $1 \mathrm{~h}$ (10). The pieces were purified and concentrated on a C18 Discovery DSC-18 SPE column (Sigma-Aldrich), then lyophilized and maintained at $-20^{\circ} \mathrm{C}(10)$. Just prior to LC-MS/MS analysis, the samples were resuspended in $20 \mu \mathrm{l}$ of Buffer A ( $0.1 \%$ formic acid in $2 \%$ acetonitrile).

Mass spectrometry and database search. The samples were analyzed using a QStar Elite mass spectrometer (Applied Biosystems) coupled with an Dionex UltiMate 3000 liquid 
chromatography system (Amsterdam, The Netherlands) $(9,10)$. For each analysis, samples were loaded onto a C18 PepMap column (Dionex) at a flow rate of $300 \mathrm{nl} / \mathrm{min}$. A $125-\mathrm{min}$ gradient was generated between Buffer A and Buffer B $(98 \%$ ACN, $0.1 \% \mathrm{FA}$ ), and consisted of 3 min of both $4 \%$ Buffer B and $96 \%$ Buffer A, 7 min of $4-10 \%$ Buffer B, 55 min of $10-35 \%$ Buffer B, 25 min of 35-100\% Buffer B, 15 min of $100 \%$ Buffer $B$ and a final 20 min of $96 \%$ Buffer A (10). The mass spectrometer was set to perform data acquisition in the positive ion mode, with a selected mass range of $300-1800 \mathrm{~m} / \mathrm{z}$. The two most abundant charged ions which exceeded 20 counts were chosen for MS/MS and dynamically excluded for $30 \mathrm{sec}$ with a $\pm 50 \mathrm{mDa}$ mass tolerance (10).

ProteinPilot software (version 2.0; Applied Biosystems, MDS-Sciex) was used for protein identification and quantification. MS/MS data were searched against the International Protein Index (IPI) human database v3.77. The database was searched by setting a fixed modification of cysteine using MMTS. Other parameters included oxidation of methionine, iTRAQ labeled-lysine, N-terminal iTRAQ labeling, MS/MS tolerance: $0.5 \mathrm{Da}$, and a maximum of one missed cleavage. The relative quantification of each peptide in the case of ITRAQ was determined on the MS/MS scans using the peak areas of 117, 118, 119 and $121 \mathrm{Da}$. The Paragon Algorithm embedded in ProteinPilot V2.0 software was used for the statistical calculation. In brief, protein identification was based on 3 or more unique peptides, of $>95 \%$ confidence, being assigned.

RNA extraction and quantitative RT-PCR. Total RNA was extracted with a TRIzol reagent (Gibco-BRL, Gaithersburg, MD, USA) according to the manufacturer's instructions. First-strand cDNA was synthesized from $2 \mu \mathrm{g}$ of total RNA, using A3500 Reverse transcription system (Promega). RT-PCR was performed on an ABI 7900HT system using the Taq-Man Gene Expression Assay kit and following primers for GAPDH (Hs00486019_CE), NAPSA (Hs00188200_CE), KRT1 (Hs00459308_CE), BCAM (Hs00185951_CE), OLFM4 (Hs00447959_CE), LGALS7 (Hs00355547_CE), LGALS3BP (Hs00417610_CE), IDH2 (Hs00475823_CE), GDI1 (Hs00401968_CE), EPX (Hs00169490_CE), FKBP9 (Hs00405072_CE), HNRNPAB (Hs00269605_CE), LASP1 (Hs00348599_CE), FGB (Hs00255169_CE), CPVL (Hs00507250_CE), ACAT1 (Hs00111889_CE), CALD1 (Hs00372592_CE), ATP5L (Hs00334349_CE), BASP1 (Hs00258102_CE), ATP5B (Hs00481655_CE), APCS (Hs00289738_CE), VIL1 (Hs00206299_CE) and AZU1 (Hs00177715_CE). Relative expression was calculated according to the $2^{-\Delta \Delta \mathrm{CT}}$ quantification method (11).

Immunoblot analysis. The cells/tissues were lysed for $30 \mathrm{~min}$ at $4^{\circ} \mathrm{C}$ in a non-ionic detergent (NID) lysis buffer containing $1 \mathrm{mM}, \mathrm{pH}$ 8.0 EDTA, 0.5\% IGEPAL, $50 \mathrm{mM}, \mathrm{pH} 7.5$ Tris- $\mathrm{HCl}$, $50 \mathrm{mM}$ sodium fluoride, $150 \mathrm{mM} \mathrm{NaCl}, 1 \mathrm{mM}$ sodium orthovanadate, $0.5 \%$ Triton-X and protease inhibitors (11). Approximately $20 \mu \mathrm{g}$ of the protein specimens were separated with the use of SDS-polyacrylamide and transferred onto PVDF membranes (Amersham Biosciences). After blocking with 5\% non-fat powdered milk in TBS-T buffer ( $\mathrm{pH} 7.6,0.5 \%$ Tween-20), the monoclonal antibodies against Azurocidin 1 (AZU1), CPVL, OLFM4, Villin 1 (VIL1), transducer and activator of transcription 3 (STAT3), phosphorylated STAT3 (pY705-STAT3), matrix metalloproteinase 9 (MMP9), matrix metalloproteinase 2 (MMP2), and actin from Abcam (Cambridge, MA, USA) were incubated at a dilution of 1:500-1:1,000 at normal temperature for $2 \mathrm{~h}$. A horseradish peroxidase-conjugated goat anti-mouse IgG or goat anti-rabbit IgG (Amersham Biosciences) was incubated at a dilution of 1:5,000 for $1 \mathrm{~h}$ at room temperature. All of the blots were developed by the enhanced chemiluminescence (ECL) system obtained from Amersham Biosciences (Uppsala, Sweden).

Immunohistochemistry (IHC) and tissue microarrays (TMA). The tissue microarrays (LV801a) obtained from US Biomax Inc. (Rockville, MD, USA) contain formalin-fixed paraffin embedded samples of 40 cases of gastric cancer and 40 matched or unmatched cancer adjacent normal, single core tissues. Immunohistochemistry of TMA was carried out as previously reported (12). After dewaxing with xylene, sections were rehydrated using an alcohol gradient $(100,95$ and $70 \%$ ) and finally washed in double-distilled $\mathrm{H}_{2} \mathrm{O}(12)$. After quenching endogenous peroxidase activity with $3 \% \mathrm{H}_{2} \mathrm{O}_{2}$ for $10 \mathrm{~min}$ and blocking with BSA for $30 \mathrm{~min}$, the sections were incubated with antibodies against AZU1, CPVL, OLFM4, and VIL1 (1:100) overnight at $4^{\circ} \mathrm{C}$. Detection was achieved with the Envision/horseradish peroxidase system (DakoCytomation, Glostrup, Denmark) (12). All slides were counterstained with Gill's hematoxylin for $1 \mathrm{~min}$, dehydrated and mounted for light microscope analysis $(10,12)$.

The stained TMA slides were evaluated and scored by the same certified pathologist who was blinded to the clinical data. The protein expression was assessed using a semi-quantitative scoring consisting of an assessment of both staining intensity (scale 0-3) and the percentage of positive cells (0-100\%), which, when multiplied, generate a score ranging from 0 to 300 . The t-test was performed at $95 \%$ confidence. All the statistical analyses were performed using SPSS software for Windows, version 16.0 (SPSS, Inc., Chicago, IL, USA).

OLFM4 siRNA transfection, wound-healing, cell migration and invasion assays. AGS and MKN28 cells were transfected with negative control siRNA (12935-400) or $100 \mathrm{nM}$ of OLFM4 specific Stealth Select RNAi ${ }^{\mathrm{TM}}$ siRNA (HSS116245, HSS116246 and HSS116247) using Lipofectamine 2000 according to the manufacturer's protocol (Invitrogen-Life Technologies, Carlsbad CA, USA). Two days following transfection, wound-healing, cell migration and invasion assays were conducted. The wound healing assay was performed in 6-well plates. When the cells had grown to confluence, a wound was incised in the cell monolayer using a sterile p200 pipette tip. Images of the scratches were captured at 0 and $24 \mathrm{~h}$ using a phase contrast microscope. The rate of cell migration was determined by the extent of gap closure. The transwell migration and invasion assays were performed using a 24-well cell migration and invasion assay kit $(8 \mu \mathrm{m}$ pore size, colorimetric format) obtained from Cell Biolabs Inc. (San Diego, CA, USA) according to the manufacturer's protocol. Briefly, after being transfected with OLFM4 or control siRNA for $48 \mathrm{~h}$ and starved for $24 \mathrm{~h}$, AGS and MKN cells were harvested and resuspended in serum-free media. Approximately $3 \times 10^{5}$ cells/300 $\mu 1$ media were loaded into the upper chamber, and 


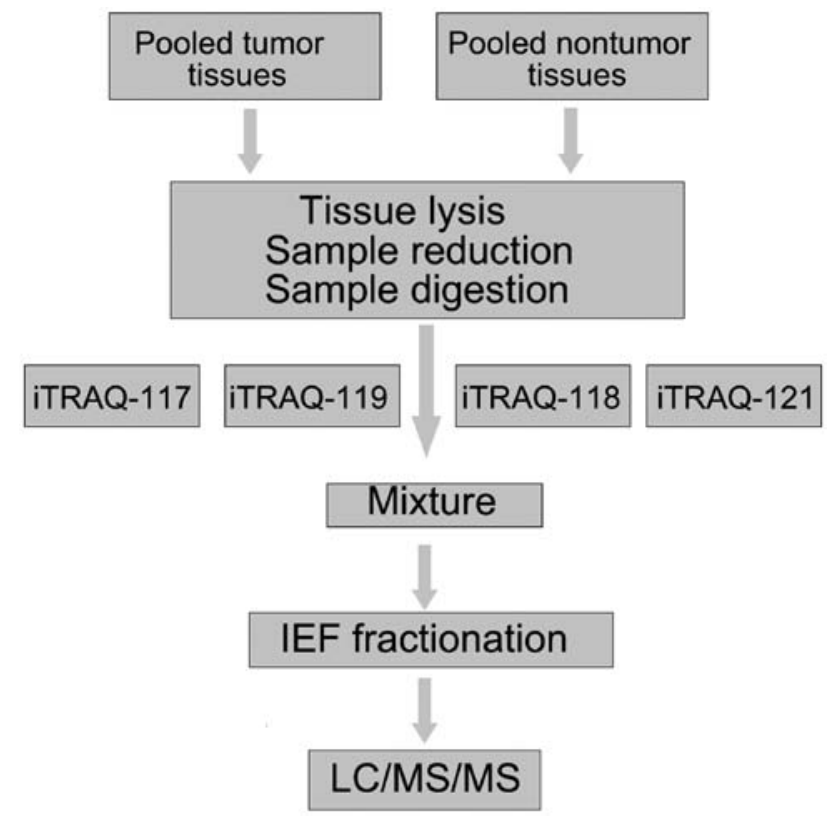

Figure 1. Flow chart of iTRAQ proteomics approach.

the lower chambers were filled with $500 \mu 1$ media (1640 plus $10 \%$ FBS). Cells were allowed to migrate or invade for 12 or $24 \mathrm{~h}$, respectively. The non-invasive cells on the top of the Transwell membrane filter inserts were removed with cotton swabs, while the migrating/invading cells on the bottom of the filters were stained, fixed, extracted, and measured at OD $560 \mathrm{~nm}$ according to the manufacturer's instructions. In each case, the silencing of protein expression was verified by western blot analysis as described above.

Cell proliferation assay. AGS and MKN28 cells were seeded onto 96-well plates at a density of $1.5 \times 10^{3}$ cells/well. Cells were cultured in RPMI-1640 media with $10 \%$ FBS and transfected with OLFM4 siRNA or control siRNA for 0, 24, 48, 72 and $96 \mathrm{~h}$ at $37^{\circ} \mathrm{C}$. The MTT assay wad performed as follows: cells were incubated with $20 \mu 1 \mathrm{MTT}$ (Sigma-Aldrich) at $37^{\circ} \mathrm{C}$ for $4 \mathrm{~h}$. The MTT substrate was then dissolved in $200 \mu \mathrm{l}$ of DMSO (Sigma-Aldrich) for $5 \mathrm{~min}$. Finally the absorbance was measured at $570 \mathrm{~nm}$.

Statistical analysis. All experiments were performed at least in triplicate. The data were plotted as mean \pm standard deviation (SD) and performed with the Student's t-test between the two groups. A P-value of $<0.05$ was considered statistically significant.

\section{Results}

Analysis of iTRAQ data of aberrantly expressed proteins. We used the iTRAQ quantification to investigate the mechanism of GC. The ITRAQ assay was performed on pooled tumor tissues and pooled non-tumor tissues. To improve the confidence and enhance the range of protein identification, specimens were iTRAQ labeled in duplicate. Fig. 1 shows the flow chart of iTRAQ proteomics approach. The ratio of 117:118 and 119:121 expressed the relative protein expression in the GC tissues compared to non-cancer tissues, which were used as a control group.

For protein quantitation and identification, we used ProteinPilot 2.0 software to identify hundreds of proteins. The protein threshold was set to achieve $95 \%$ confidence at $5 \%$ FDR (false discovery rate). To classify proteins as upregulated or downregulated, we introduced an additional 1.3-fold cut-off for all iTRAQ ratios (10,13-16). Therefore, proteins with iTRAQ ratios $<0.77(1 / 1.3)$ or $>1.3(1.3 / 1)$-fold cut-off $(\mathrm{P}<0.05)$ were considered to be downregulated or upregulated, respectively $(13,17)$. The technical variation of data from duplicate experiments was $<30 \%(12,14,18-21)$. A total of 753 unique proteins were identified with $95 \%$ confidence, regardless of whether or not there was a significant P-value in the iTRAQ ratios. A total of 134 proteins were expressed differently in gastric cancer compared to non-cancer tissues (51 overexpressed and 83 downregulated proteins). Due to limitations of space, only the top 30 downregulated and upregulated proteins in both pooled non-cancer tissues and pooled cancer tissues are shown in Table II.

Cellular and molecular functional characteristics of the proteins. To better identify the functional characteristics, the 134 aberrantly expressed proteins were uploaded into PANTHER (www.pantherdb.org/) and grouped on the basis of their reported biological processes and molecular functions.

The identities of a total of 134 proteins and their molecular functions are shown in Fig. 2, which include 12 biological processes, 25 protein classes and 9 molecular functions. Metabolic, cellular and developmental processes were the most common biological processes reported.

Validation of iTRAQ identified candidate proteins. To validate the observed protein changes, western blotting and RT-PCR were performed with identical pooled cancer samples and non-cancer samples used in the iTRAQ assay. Fig. 3A shows that AZU1, CPVL, OLFM4 and VIL1 were obviously increased in the gastric cancer tissues, compared with normal gastric tissues. Although each immunoblot had its own control, only one representative actin blot is shown. Fig. 3B shows the mRNA expression levels of NAPSA, KRT1, BCAM, OLFM4, LGALS7, LGALS3BP, IDH2, GDI1, EPX, FKBP9, HNRNPAB, LASP1, FGB, CPVL, ACAT1, CALD1, ATP5L, BASP1, ATP5B, APCS, VIL1, AZU1 and HEXB as standardized to GADPH. As expected, the mRNA levels of KRT1, OLFM4, LGALS7, LGALS3BP, EPX, FKBP9, LASP1, FGB, CPVL, CALD1, VIL1, HEXB, BASP1, AZU1 and HNRNPAB were found to be increased in gastric cancer tissues, whereas the levels of NAPSA, BCAM, IDH2, GDI1, ACAT1, ATP5L, ATP5B and APCS were decreased, compared to non-cancer tissues. These results correspond with that revealed by iTRAQ. Similarly, IHC (immunohistochemistry) in tissue microarrays of gastric cancer tissues and non-cancerous tissues proved that gastric cancer tissues expressed increased AZU1, CPVL, OLFM4 and VIL1 immunostaining compared to control tissues (Fig. 4).

OLFM4 plays a role in GC cell invasion, migration and wound healing and proliferation. Since we observed that the upregulation of OLFM4 in gastric cancer is a frequent event 


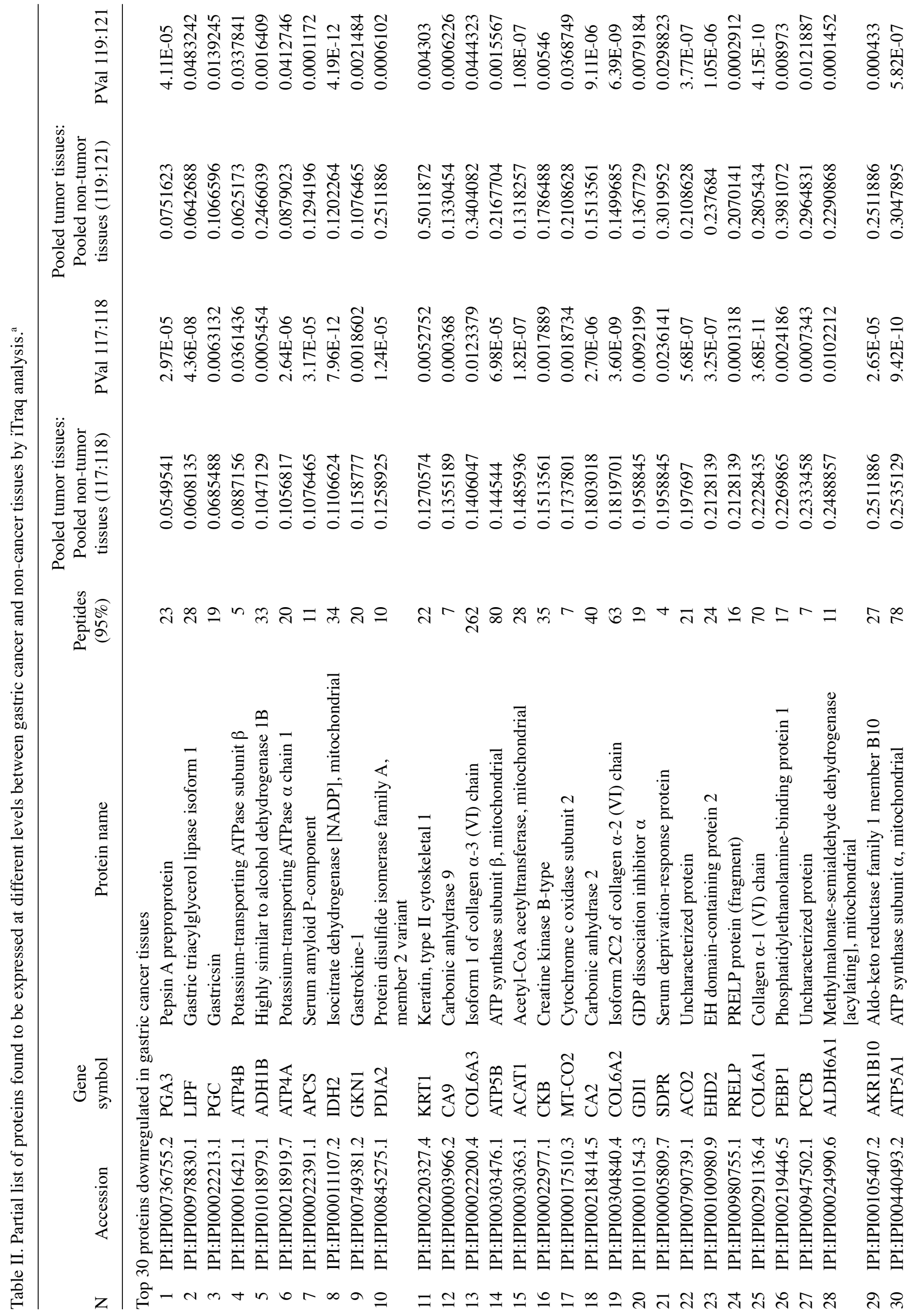




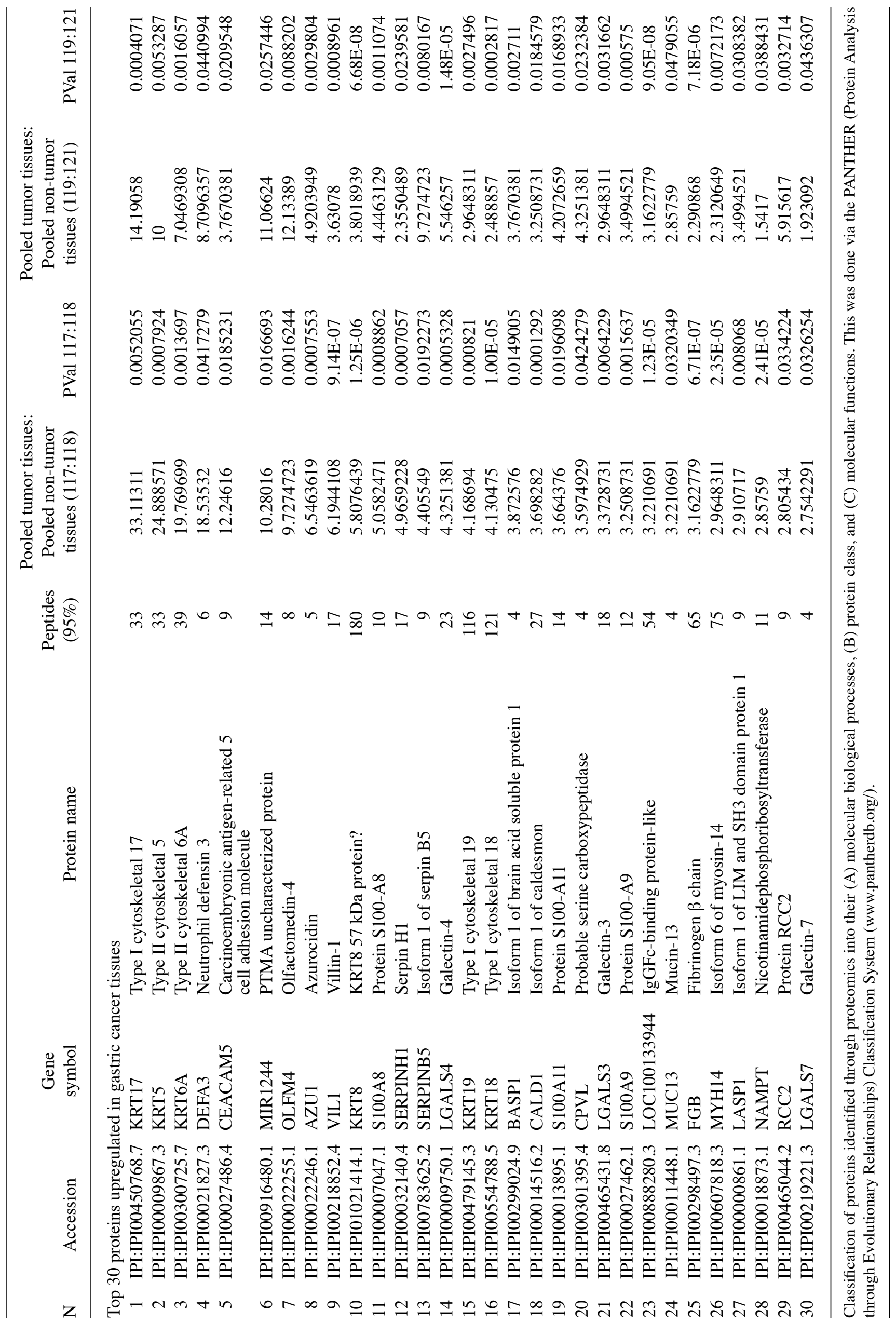


A

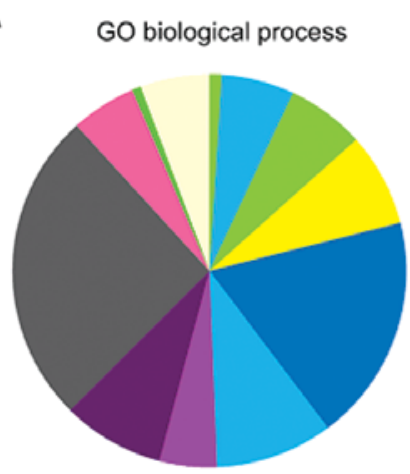

B

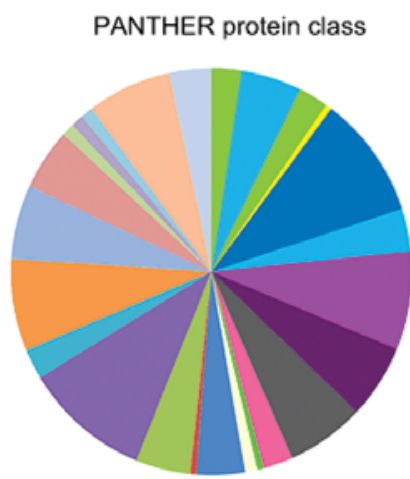

C

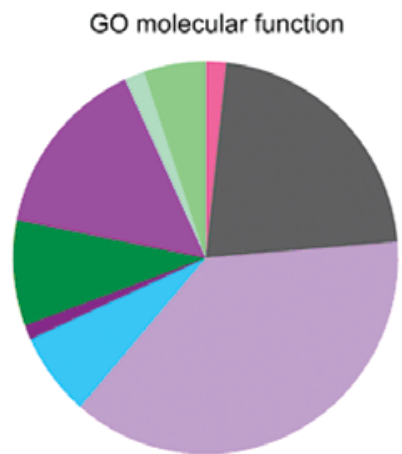

= apoptotic process(GO:0006915) $1.0 \%$

- biological adhesion(GO:0022610) $6.0 \%$

= biological regulation(GO:0065007) $6.4 \%$

- cellular component organization or biogenesis(GO:0071840) $7.7 \%$

- cellular process(GO:0009987) $18.7 \%$

n developmental process(GO:0032502) $9.7 \%$

- immune system process(GO:0002376) $4.7 \%$

- localization(GO:0051179) $8.4 \%$

- metabolic process(GO:0008152) $25.8 \%$

- multicellular organismal process(GO:0032501) $5.4 \%$

- reproduction(GO:0000003) $0.7 \%$

response to stimulus(GO:0050896) $5.7 \%$

In calcium-binding protein(PC00060) $2.4 \%$

- cell adhesion molecule(PC00069) 4.9\%

= cell junction protein (PC00070) $2.4 \%$

- chaperone (PC00072) 0.5\%

- cytoskeletal protein (PC00085) 9.8\%

defense/immunity protein (PC00090) $3.4 \%$

n enzyme modulator (PC00095) $7.8 \%$

- extracellular matrix protein (PC00102) $5.9 \%$

- hydrolase (PC00121) $6.3 \%$

- isomerase (PC00135) 2.4\%

घinase (PC00137) $0.5 \%$

ligase (PC00142) $\quad 1.0 \%$

- lyase (PC00144) 3.9\%

- membrane traffic protein (PC00150) $\quad 0.5 \%$

nucleic acid binding (PC00171) $\quad 4.4 \%$

n oxidoreductase (PC00176) 10.2\%

- protease (PC00190) $2.4 \%$

- receptor (PC00197) 7.3\%

= signaling molecule (PC00207) $5.9 \%$

- structural protein (PC00211) $4.9 \%$

- surfactant (PC00212) $\quad 1.0 \%$

= transcription factor (PC00218) $1.0 \%$

- transfer/carrier protein (PC00219) $1.0 \%$

= transferase $(\mathrm{PC} 00220) \quad 6.8 \%$

= transporter ( $\mathrm{PC} 00227) \quad 3.4 \%$

m antioxidant activity (GO:0016209) $1.7 \%$

- binding (GO:0005488) 22\%

= catalytic activity (GO:0003824) $37.6 \%$

= enzyme regulator activity (GO:0030234) $6.9 \%$

- nucleic acid binding transcription factor activity (GO:0001071) $1.2 \%$

- receptor activity (GO:0004872) $8.7 \%$

- structural molecule activity (GO:0005198) $15.0 \%$

$=$ translation regulator activity (GO:0045182) $\quad 1.7 \%$

$=$ transporter activity (GO:0005215) $5.2 \%$

Figure 2. Classification of proteins identified through proteomics into their (A) molecular biological processes, (B) protein class, and (C) molecular functions. This was done via the PANTHER (Protein Analysis through Evolutionary Relationships) Classification System (www.pantherdb.org/).

and closely associated with gastric cancer metastasis, we postulated that overexpression of OLFM4 in gastric cancer cells can promote cell migration and invasion. Thus, we used siRNA technology to inhibit OLFM4 expression in gastric cancer cell lines. AGS cells and MKN28 cells were transfected with OLFM4-specific siRNA sequences. According to western blot analysis, efficient silencing of OLFM4 expression was demonstrated by the OLFM4-specific siRNA sequences (Fig. 5A). Using RNA interference, we saw that the downregulation of OLFM4 markedly inhibited the invasion of AGS and
MKN28 cells by $48-50$ and $41-50 \%$, respectively, compared to the controls $(\mathrm{P}<0.05)$ (Fig. 5B). The migration assay proved that OLFM4-specific siRNAs weakened the migration of AGS cells and MKN28 cells by 43-49 and 44-54\%, respectively, in comparison with control siRNA ( $\mathrm{P}<0.05)$ (Fig. 5C). Similarly, the ability to close scratch wounds was decreased in AGS and MKN28 cells (Fig. 5D). We also used the MTS assay to examine the proliferation of OLFM4-silenced vs. control AGS cells and MKN28 cells. The proliferation of AGS cells and MKN28 cells was depressed compared to the control cells, 
A

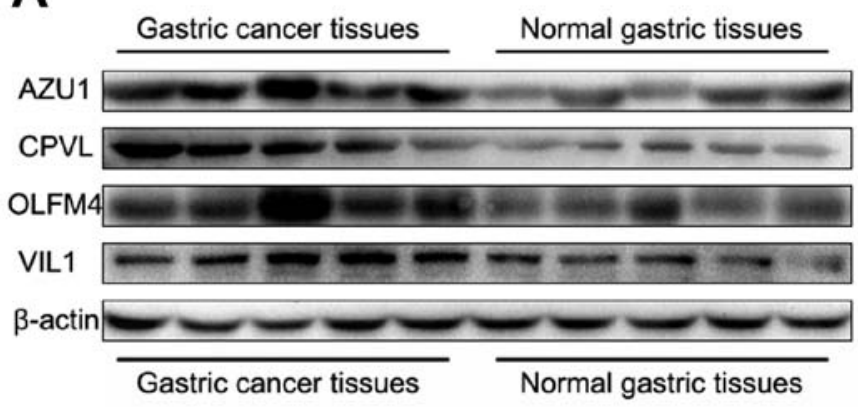

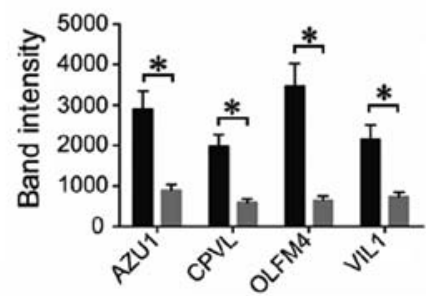

B

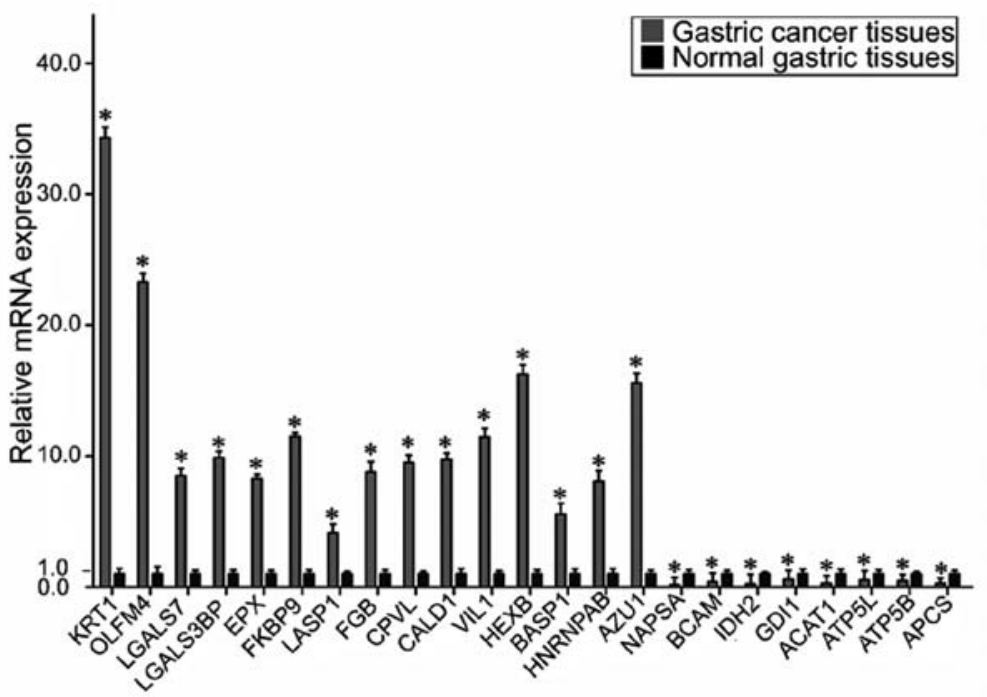

Figure 3. Evaluation of the differentially expressed proteins in gastric cancer tissues and normal gastric tissues. (A) A representative western blot analysis for AZU1, CPVL, OLFM4 and VIL1 expression in gastric cancer tissues and normal gastric tissues. The expression of proteins AZU1, CPVL, OLFM4 and VIL1 was significantly increased in cancer tissues compared to normal gastric tissues (bars indicate SD, ${ }^{*} \mathrm{P}<0.05$ ). Actin was used as the normalization standard. (B) Real-time RT-PCR detected the relative mRNA expression levels of NAPSA, KRT1, BCAM, OLFM4, LGALS7, LGALS3BP, IDH2, GDI1, EPX, FKBP9, HNRNPAB, LASP1, FGB, CPVL, ACAT1, CALD1, ATP5L, BASP1, ATP5B, APCS, VIL1, AZU1 and HEXB as normalized to GADPH (P<0.05).

indicating that OLFM4 plays a crucial role in GC cell proliferation (Fig. 5E).

Knockdown of OLFM4 suppresses p-STAT3, MMP9 and $M M P 2$ protein expression. The expression of p-STAT3, STAT3, MMP9 and MMP2 are known to participate in the pathogenic mechanism of tumor metastasis (22-24). To inspect the role of differential OLFM4 expression, the protein levels of STAT3, p-STAT3, MMP9 and MMP2 were evaluated in GC cells following OLFM4 silencing. We observed that the downregulation of OLFM4 inhibits p-STAT3, MMP9 and MMP2 expression at the protein level in AGS cells $(\mathrm{P}<0.05)$ (Fig. 6). A consistent phenotype was also observed in MKN28 cells after OLFM4 silencing (data not shown).

\section{Discussion}

Gastric cancer is one of the most frequent malignant tumors worldwide with a high mortality and morbidity. Surgery and chemotherapy are the mainstream methods of treating this malignancy, but vast majority of patients have already metastasis by the time a diagnosis is made. The prognosis of these patients is still very poor after operation and chemotherapy (25). The 5-year survival rate is obviously decreased for patients with metastasis, compared to patients diagnosed early (2). Investigations into the molecular mechanisms involved in gastric cancer progression are necessary and may provide insights leading to improved diagnosis and therapeutic approaches.

The present study used the iTRAQ based proteomics method to confirm proteins with differential expressions between patient samples of gastric cancer tissues and noncancerous tissues. As a result, 134 aberrantly proteins were identified in gastric cancer samples. Many of them, including AZU1, CPVL, OLFM4 and VIL1 were identified using western blot analyis, RT-PCR and IHC. The data indicated that the iTRAQ labeling method is both reliable and powerful for protein quantification. Moreover, OLFM4 has been proven to be associated with GC cell invasion, migration and proliferation. The invasion and migration of tumor cells is an important biological behavior of a tumor and is closely related to the prognosis of the disease. Furthermore, suppression of OLFM4 expression may be a promising strategy in the development of novel cancer therapeutic drugs. We discuss below several key proteins identified in the present study.

Olfactomedin4 (also called as GW112) is an important member of the family of olfactomedin (26). The protein sequences within OLF domains are comprised of approxi- 

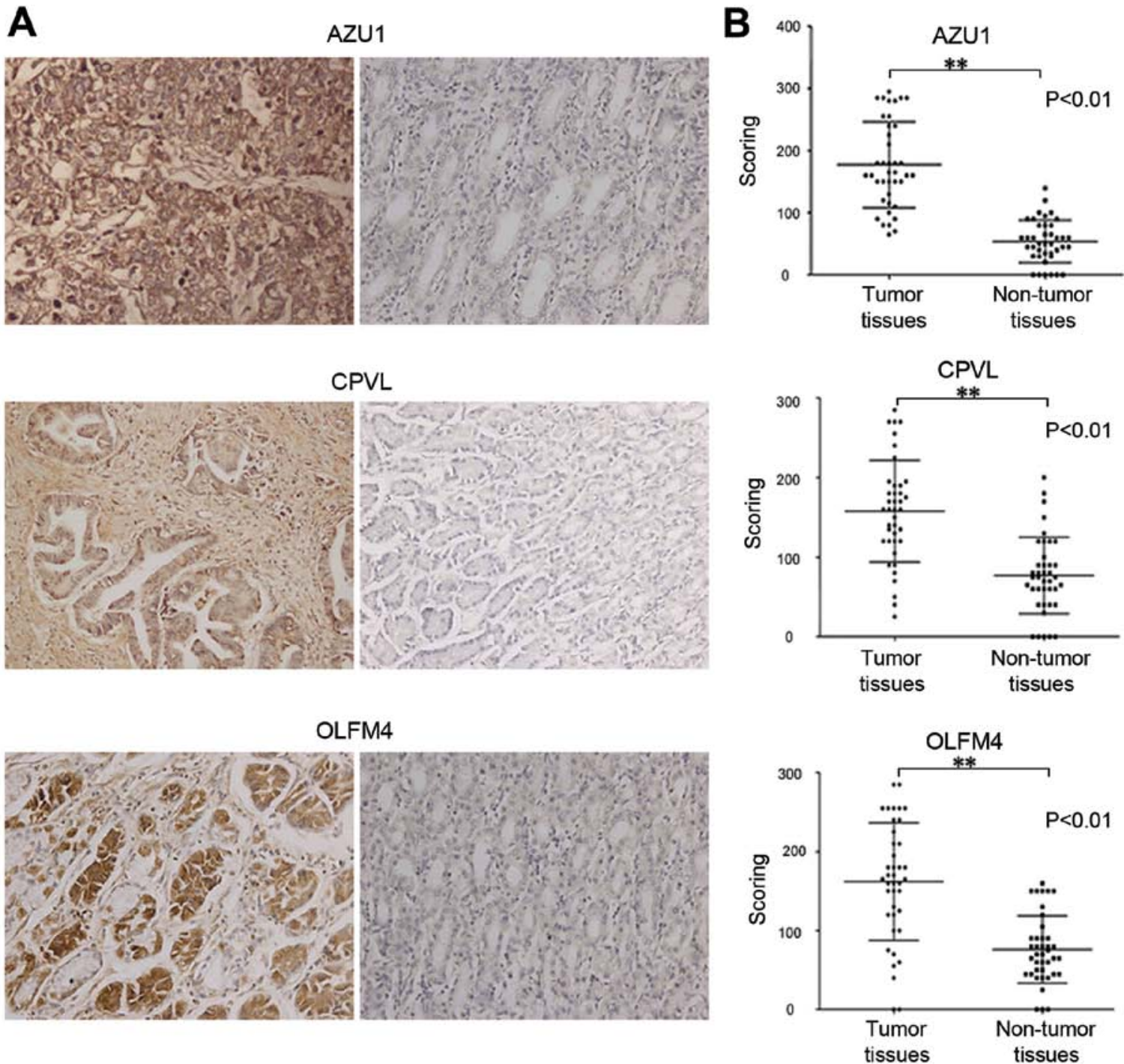

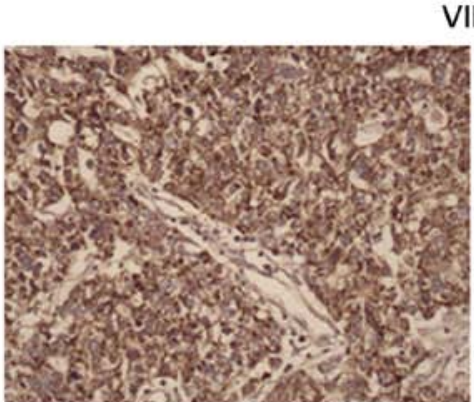

Tumor tissues

VIL1

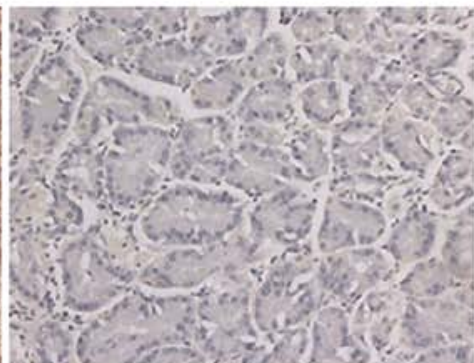

Non-tumor tissues

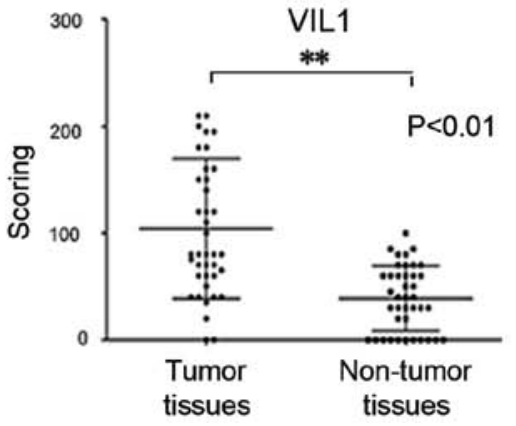

Figure 4. Immunohistochemistry (IHC) for AZU1, CPVL, OLFM4 and VIL1. (A) Representative immunohistochemistry images of AZU1, CPVL, OLFM4 and VIL1. (B) Corresponding scorings from tumorous and non-tumorous tissue microarray samples. IHC scores for AZU1, CPVL, OLFM4, and VIL1 were obviously higher in tumor tissues than in non-tumor tissues $\left({ }^{* *} \mathrm{P}<0.01\right)$.

mately 260 amino acids (27). They play a significant role in maintaining the stability of various biological functions, including neural occurrence, intercellular adhesion, cell cycle regulation and apoptosis (28). The unique functional structure and capability of OLFM4 suggests it can promote the occurrence and developmental progress of malignant tumors. Previous studies indicated that OLFM4 was overexpressed in malignancies, including pancreatic carcinoma, lung carcinoma, breast carcinoma and colorectal carcinoma (29-33).
For example, it was proven that OLFM4 mRNA was upregulated in cancerous tissues of the colon, breast and lungs (32). In the secreted proteins of head and neck squamous cells, OLFM4 was found to be present in higher abundance (33). Zhang et al (34) showed that forced overexpression of OLFM4 in prostate cancer cells led to increased oncogenesis and strongly suggested that OLFM4 is a significant regulator of cell death, which plays significant roles in cancer cell survival and cancer growth. 


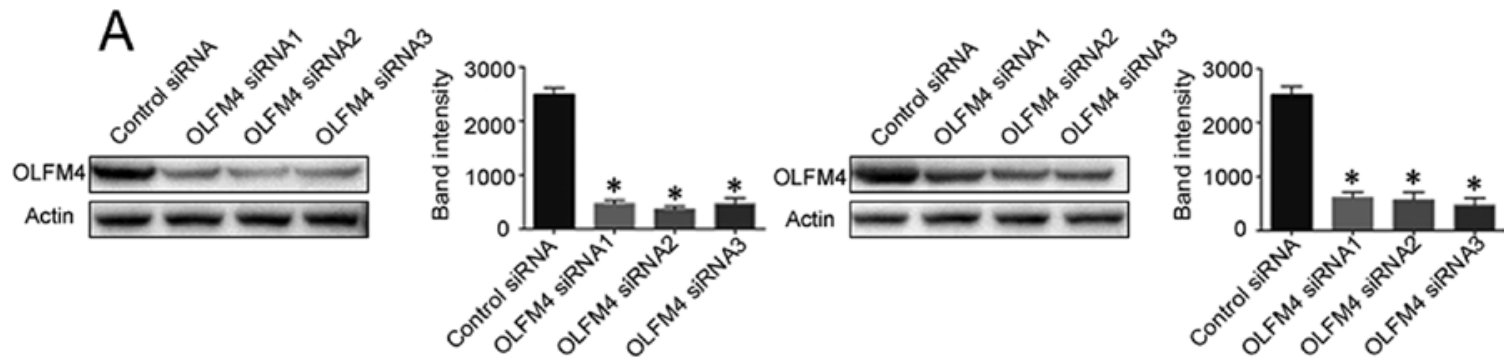

B Effect of OLFM4 knockdown on AGS cell invasion

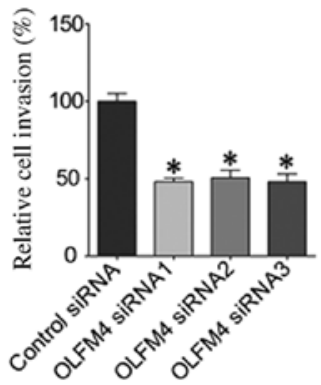

Effect of OLFM4 knockdown on MKN28 cell invasion

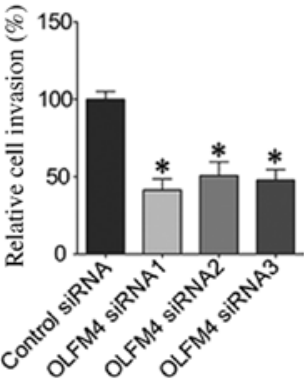

C

Effect of OLFM4 knockdown on AGS cell migration

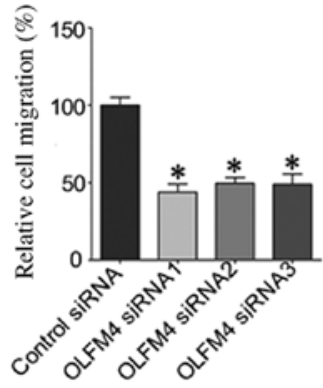

Effect of OLFM4 knockdown on MKN28 cell migration
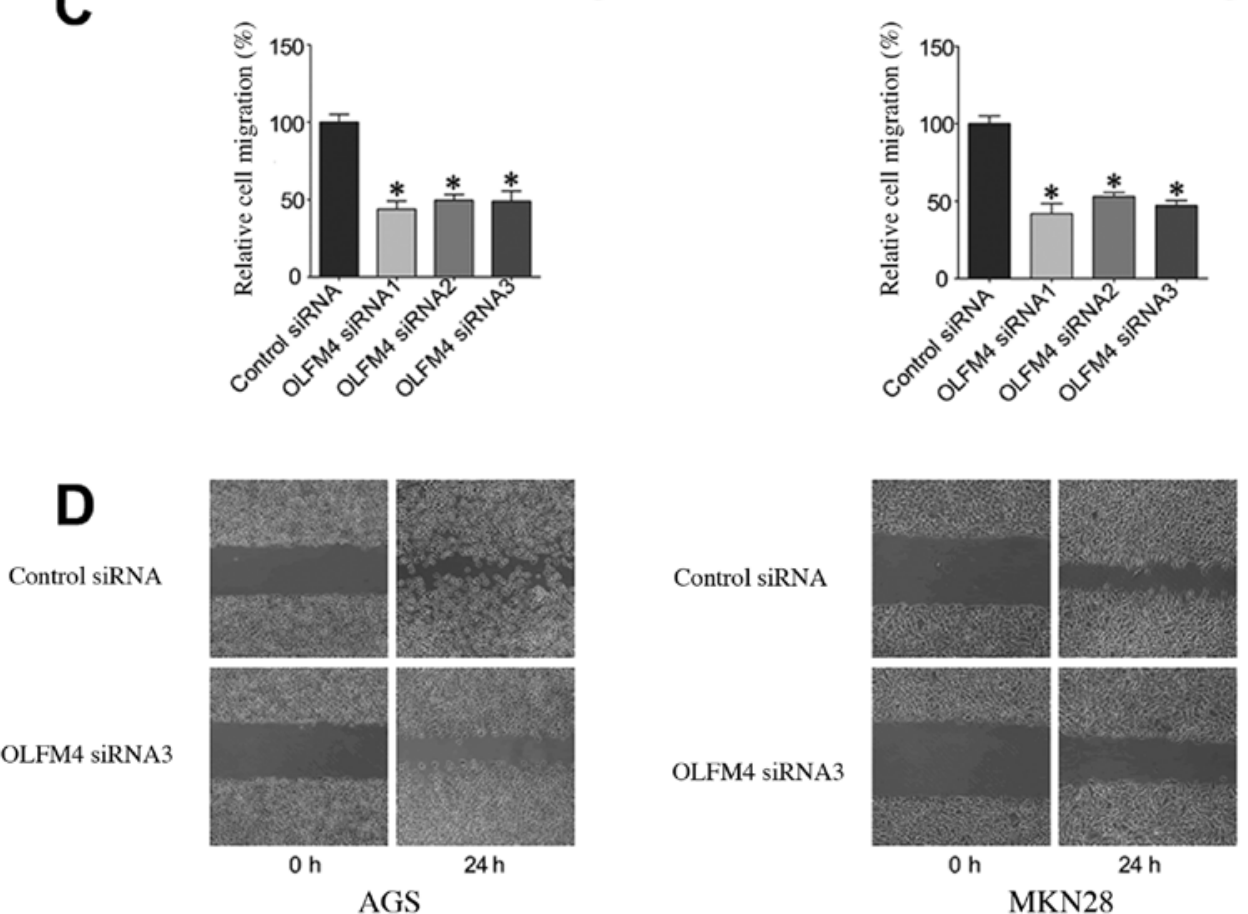

E Effect of OLFM4 knockdown on AGS cell proliferation
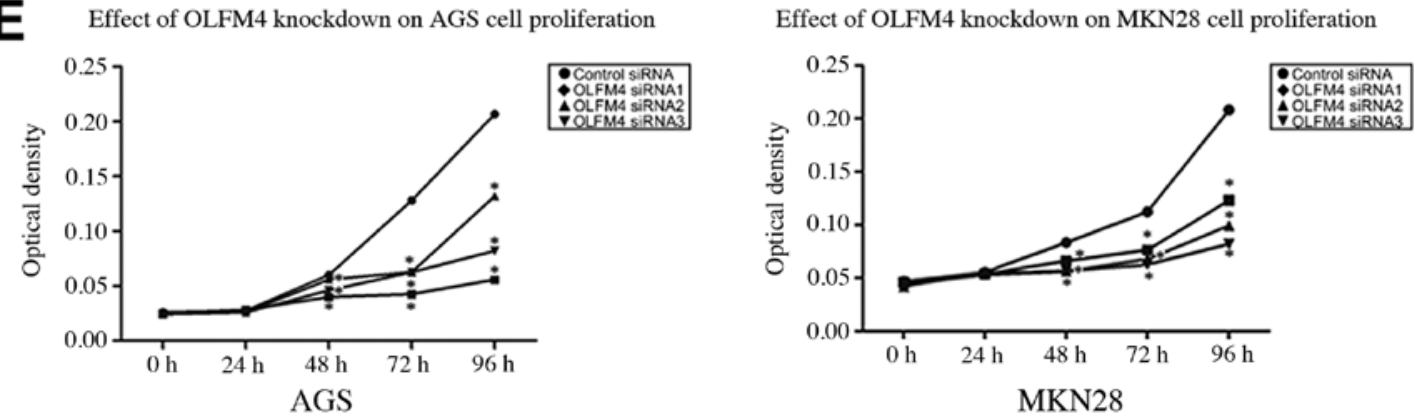

Figure 5. Functional studies of OLFM4 in gastric cancer cell lines. (A) Western blot analysis showed that the silencing of OLFM4 by three different genespecific siRNA sequences significantly reduced OLFM4 protein levels in cell lysates of AGS and MKN28, compared to the controls. (B) Silencing of OLFM4 by the three gene-specific siRNAs significantly inhibited the invasiveness of gastric cancer cell lines AGS and MKN28, compared to control siRNA. (C) The migration ability was significantly inhibited in cells transfected with OLFM4-specific siRNAs. (D) Wound healing and (E) proliferation were significantly inhibited in cells transfected with OLFM4-specific siRNAs ( $\mathrm{P}<0.05)$. 

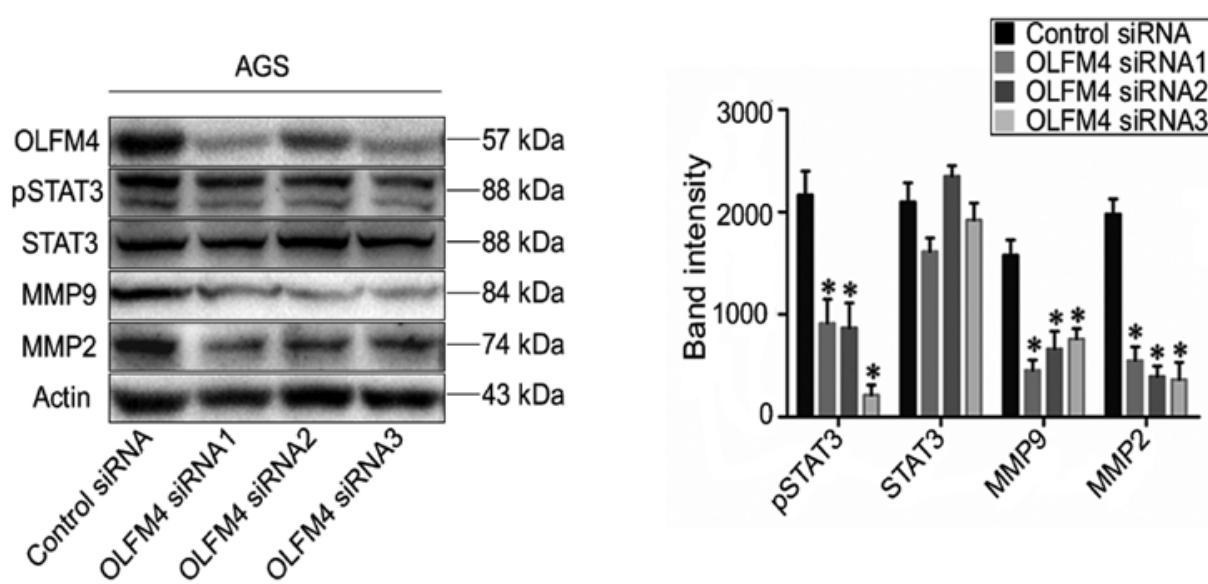

Figure 6. Western blot analysis of STAT3, p-STAT3, MMP9 and MMP2. Protein levels from AGS cells transfected with OLFM4-specific or control siRNAs were analyzed by western blot analysis. Band intensity analysis shows significant reduction of p-STAT3, MMP9, and MMP2 after OLFM4 silencing, but not STAT3 $\left({ }^{*} \mathrm{P}<0.05\right)$.

There have been few studies on the function of OLFM4 in gastric cancer cells. We discovered that OLFM4 was significantly overexpressed in GC tissues compared to non-cancer tissues, and also investigated the invasion and migration of gastric cancer cells by silencing OLFM4. The present study revealed that siRNA-mediated downregulation of OLFM4 significantly weakened the invasive and migratory properties of AGS and MKN28 cells in vitro. Previous studies proved that OLFM4 is an extra-cellular matrix glycoprotein, which is mediated by endogenous cell surface lectins and cadherin (35). Alterations in migratory and adhesive capabilities allow cancer cells to deviate from the structure of normal tissue and to advance in their malignant progression. OLFM4 also interacts with GRIM-19, a potent apoptotic inducer, and bound to lectins and cadherins $(33,36)$. Indeed, we obtained identical results and showed that OLFM4 induces the proliferation of AGS and MKN28 cells. Collectively, the evidence suggests that OLFM4 may be involved in gastric cancer cell migration, invasion and progression. These results suggest that the involvement of OLFM4 in GC progression make it a feasible therapeutic and prognostic tool.

It has been reported that activation of STAT3 signaling pathway is involved in the migration of cancer cells $(22,23)$. In the present study, we observed that the upregulation of OLFM4 is closely associated with gastric cancer metastasis. Thus, we speculate that OLFM4 is involved in the STAT3 pathway on the basis of these observations. In line with this, we found that the expression of MMP9, MMP2 and STAT3 activation was decreased after the silencing of OLFM4 in GC cell lines. Yoon et al (37) showed that STAT3 is activated by an inherent mechanism under the stressful conditions of cancer cells, and it induced various survival factors. In conclusion, the above suggests that OLFM4 may contribute to the STAT3 signaling pathway in GC.

Apart from OLFM4, other proteins having associations with gastric cancer were identified in the present study with supporting literary evidence include VIL1, which was discovered to be at differential levels in GC patients. VIL1 was selected for confirmation analysis by western blotting, RT-PCR and IHC. Previous studies have reported that VIL1 is an actin-modifying protein that regulates the restructuring of microvillar actin filaments $(38,39)$. Osborn et al $(40)$ proved that VIL1 was involved in intestinal metaplasia and gastric carcinoma. VIL1 was useful for distinguishing normally differentiated epithelial cells from the simple epithelia lining the gastrointestinal tract (41). Upregulation of VIL1 was observed in HCC tissues (42). VIL1 may be a biomarker of metastatic adenocarcinomas.

Another candidate protein in the study found to be markedly upregulated in GC tissues was AZU1 (also known as CAP37), an antimicrobial protein. Interestingly, AZU1 is considered as a chemoattractant for monocytes (43). Raff et al (44) used a model to predict that changes in AZU1 action could affect cancer progression but were unlikely to be the major cause of carcinoma. Considering these known functions of AZU1, AZU1 may play an important role in GC.

CPVL was also confirmed in the present study as an increased protein in GC tissues. CPVL may play an important role in antigen presentation, including trimming of peptides, digesting phagocytosed particles in the lysosome, and participating in an inflammatory protease cascade (45). However, the link between CPVL and gastric cancer requires further investigation.

In conclusion, we have performed a comparative proteomic profile between gastric cancer tissues and adjacent non-cancer tissues. The resulting datasets of GC proteins supplied a useful resource for fundamental and translational study. In addition, we observed that overexpression of OLFM4 may induce the development and metastasis of gastric cancer. OLFM4 may play a new role in the development of gastric cancer, and reveals its impact in gastric cancer cell proliferation and cancer metastasis. Furthermore, suppression of the OLFM4 expression may be a hopeful strategy in developing new therapeutic drugs. These findings supply insight into novel candidate proteins that represent critical malignant mechanisms that may be accessible targets useful for GC therapeutic strategies.

\section{Acknowledgements}

The present study was supported by the National Natural Science Foundation of China (nos. 81171560, 30930082, 81171561, 30972584 and 81372399), the National Science 
and Technology Major Project of China (2008ZX10002-006, 2012ZX1002007001, 2011ZX09302005, 2012ZX09303001001 and 2012ZX10002003).

\section{References}

1. Loomis D, Huang W and Chen G: The International Agency for Research on Cancer (IARC) evaluation of the carcinogenicity of outdoor air pollution: Focus on China. Chin J Cancer 33: 189-196, 2014.

2. Takeno S, Noguchi T, Kikuchi R, Sato T, Uchida Y and Yokoyama S: Analysis of the survival period in resectable stage IV gastric cancer. Ann Surg Oncol 8: 215-221, 2001.

3. Klose $\mathbf{J}$ and Kobalz U: Two-dimensional electrophoresis of proteins: An updated protocol and implications for a functional analysis of the genome. Electrophoresis 16: 1034-1059, 1995.

4. Görg A, Obermaier C, Boguth G, Harder A, Scheibe B, Wildgruber $\mathrm{R}$ and Weiss $\mathrm{W}$ : The current state of two-dimensional electrophoresis with immobilized $\mathrm{pH}$ gradients. Electrophoresis 21: 1037-1053, 2000

5. Ross PL, Huang YN, Marchese JN, Williamson B, Parker K, Hattan S, Khainovski N, Pillai S, Dey S, Daniels S, et al: Multiplexed protein quantitation in Saccharomyces cerevisiae using amine-reactive isobaric tagging reagents. Mol Cell Proteomics 3: 1154-1169, 2004.

6. Gygi SP, Rist B, Gerber SA, Turecek F, Gelb MH and Aebersold R: Quantitative analysis of complex protein mixtures using isotopecoded affinity tags. Nat Biotechnol 17: 994-999, 1999.

7. Mirgorodskaya OA, Kozmin YP, Titov MI, Körner R, Sönksen CP and Roepstorff P: Quantitation of peptides and proteins by matrix-assisted laser desorption/ionization mass spectrometry using (18)O-labeled internal standards. Rapid Commun Mass Spectrom 14: 1226-1232, 2000.

8. Ong SE, Blagoev B, Kratchmarova I, Kristensen DB, Steen H, Pandey A and Mann M: Stable isotope labeling by amino acids in cell culture, SILAC, as a simple and accurate approach to expression proteomics. Mol Cell Proteomics 1: 376-386, 2002.

9. Wang LN, Tong SW, Hu HD, Ye F, Li SL, Ren H, Zhang DZ, Xiang R and Yang YX: Quantitative proteome analysis of ovarian cancer tissues using a iTRAQ approach. J Cell Biochem 113: 3762-3772, 2012.

10. Yang Y, Toy W, Choong LY, Hou P, Ashktorab H, Smoot DT, Yeoh KG and Lim YP: Discovery of SLC3A2 cell membrane protein as a potential gastric cancer biomarker: Implications in molecular imaging. J Proteome Res 11: 5736-5747, 2012.

11. Livak KJ and Schmittgen TD: Analysis of relative gene expression data using real-time quantitative PCR and the $2(-\Delta \Delta C(T))$ method. Methods 25: 402-408, 2001.

12. Ho J, Kong JW, Choong LY, Loh MC, Toy W, Chong PK, Wong $\mathrm{CH}$, Wong CY, Shah N and Lim YP: Novel breast cancer metastasis-associated proteins. J Proteome Res 8: 583-594, 2009.

13. Gan CS, Chong PK, Pham TK and Wright PC: Technical, experimental, and biological variations in isobaric tags for relative and absolute quantitation (iTR AQ). J Proteome Res 6: 821-827, 2007.

14. Chen Y, Choong LY, Lin Q, Philp R, Wong CH, Ang BK, Tan YL, Loh MC, Hew CL, Shah N, et al: Differential expression of novel tyrosine kinase substrates during breast cancer development. Mol Cell Proteomics 6: 2072-2087, 2007.

15. Chong PK, Lee H, Zhou J, Liu SC, Loh MC, So JB, Lim KH, Yeoh KG and Lim YP: Reduced plasma APOA1 level is associated with gastric tumor growth in MKN45 mouse xenograft model. J Proteomics 73: 1632-1640, 2010.

16. Pierce A, Unwin RD, Evans CA, Griffiths S, Carney L, Zhang L, Jaworska E, Lee CF, Blinco D, Okoniewski MJ, et al: Eightchannel iTRAQ enables comparison of the activity of six leukemogenic tyrosine kinases. Mol Cell Proteomics 7: 853-863, 2008.

17. Zhou C, Simpson KL, Lancashire LJ, Walker MJ, Dawson MJ, Unwin RD, Rembielak A, Price P, West C, Dive C, et al: Statistical considerations of optimal study design for human plasma proteomics and biomarker discovery. J Proteome Res 11: 2103-2113, 2012

18. Chong PK, Lee H, Loh MC, Choong LY, Lin Q, So JB, Lim KH, Soo RA, Yong WP, Chan SP, et al: Upregulation of plasma C9 protein in gastric cancer patients. Proteomics 10: 3210-3221, 2010.
19. Lim S, Choong LY, Kuan CP, Yunhao C and Lim YP: Regulation of macrophage inhibitory factor (MIF) by epidermal growth factor receptor (EGFR) in the MCF10AT model of breast cancer progression. J Proteome Res 8: 4062-4076, 2009.

20. Yang Y, Lim SK, Choong LY, Lee H, Chen Y, Chong PK, Ashktorab H, Wang TT, Salto-Tellez M, Yeoh KG, et al: Cathepsin $\mathrm{S}$ mediates gastric cancer cell migration and invasion via a putative network of metastasis-associated proteins. J Proteome Res 9: 4767-4778, 2010.

21. Choong LY, Lim S, Chong PK, Wong CY, Shah N and Lim YP: Proteome-wide profiling of the MCF10AT breast cancer progression model. PLoS One 5: e11030, 2010.

22. Xie TX, Wei D, Liu M, Gao AC, Ali-Osman F, Sawaya R and Huang S: Stat 3 activation regulates the expression of matrix metalloproteinase-2 and tumor invasion and metastasis. Oncogene 23: 3550-3560, 2004.

23. Yu H, Pardoll D and Jove R: STATs in cancer inflammation and immunity: A leading role for STAT3. Nat Rev Cancer 9: 798-809, 2009.

24. Huang Y, Yang M, Yang $\mathrm{H}$ and Zeng Z: Upregulation of the GRIM-19 gene suppresses invasion and metastasis of human gastric cancer SGC-7901 cell line. Exp Cell Res 316: 2061-2070, 2010.

25. Li C, Yan M, Chen J, Xiang M, Zhu ZG, Yin HR and Lin YZ: Survival benefit of non-curative gastrectomy for gastric cancer patients with synchronous distant metastasis. J Gastrointest Surg 14: 282-288, 2010.

26. Yu L, Wang L and Chen S: Olfactomedin 4, a novel marker for the differentiation and progression of gastrointestinal cancers. Neoplasma 58: 9-13, 2011.

27. Zeng LC, Han ZG and Ma WJ: Elucidation of subfamily segregation and intramolecular coevolution of the olfactomedin-like proteins by comprehensive phylogenetic analysis and gene expression pattern assessment. FEBS Lett 579: 5443-5453, 2005.

28. Tomarev SI and Nakaya N: Olfactomedin domain-containing proteins: Possible mechanisms of action and functions in normal development and pathology. Mol Neurobiol 40: 122-138, 2009

29. Liu W, Zhu J, Cao L and Rodgers GP: Expression of hGC-1 is correlated with differentiation of gastric carcinoma. Histopathology 51: 157-165, 2007.

30. Besson D1, Pavageau AH, Valo I, Bourreau A, Bélanger A, Eymerit-Morin C, Moulière A, Chassevent A, Boisdron-Celle M, Morel A, et al: A quantitative proteomic approach of the different stages of colorectal cancer establishes OLFM4 as a new nonmetastatic tumor marker. Mol Cell Proteomics 10: M111.009712, 2011.

31. Kobayashi D, Koshida S, Moriai R, Tsuji N and Watanabe N: Olfactomedin 4 promotes S-phase transition in proliferation of pancreatic cancer cells. Cancer Sci 98: 334-340, 2007.

32. Koshida S, Kobayashi D, Moriai R, Tsuji N and Watanabe N: Specific overexpression of OLFM4(GW112/HGC-1) mRNA in colon, breast and lung cancer tissues detected using quantitative analysis. Cancer Sci 98: 315-320, 2007.

33. Marimuthu A, Chavan S, Sathe G, Sahasrabuddhe NA, Srikanth SM, Renuse S, Ahmad S, Radhakrishnan A, Barbhuiya MA, Kumar RV, et al: Identification of head and neck squamous cell carcinoma biomarker candidates through proteomic analysis of cancer cell secretome. Biochim Biophys Acta 1834: 2308-2316, 2013.

34. Zhang X, Huang Q, Yang Z, Li Y and Li CY: GW112, a novel antiapoptotic protein that promotes tumor growth. Cancer Res 64: 2474-2481, 2004.

35. Liu W, Chen L, Zhu J and Rodgers GP: The glycoprotein hGC-1 binds to cadherin and lectins. Exp Cell Res 312: 1785-1797, 2006.

36. van der Flier LG, Haegebarth A, Stange DE, van de Wetering M and Clevers H: OLFM4 is a robust marker for stem cells in human intestine and marks a subset of colorectal cancer cells. Gastroenterology 137: 15-17, 2009.

37. Yoon S, Woo SU, Kang JH, Kim K, Shin HJ, Gwak HS, Park S and Chwae YJ: NF- $\mathrm{BB}$ and STAT3 cooperatively induce IL6 in starved cancer cells. Oncogene 31: 3467-3481, 2012.

38. Rousseau-Merck MF, Simon-Chazottes D, Arpin M, Pringault E, Louvard D, Guénet JL and Berger R: Localization of the villin gene on human chromosome 2q35-q36 and on mouse chromosome 1. Hum Genet 78: 130-133, 1988. 
39. Yokota E, Tominaga M, Mabuchi I, Tsuji Y, Staiger CJ, Oiwa K and Shimmen T: Plant villin, lily P-135-ABP, possesses G-actin binding activity and accelerates the polymerization and depolymerization of actin in a $\mathrm{Ca}^{2+}$-sensitive manner. Plant Cell Physiol 46: 1690-1703, 2005.

40. Osborn M, Mazzoleni G, Santini D, Marrano D, Martinelli G and Weber K: Villin, intestinal brush border hydrolases and keratin polypeptides in intestinal metaplasia and gastric cancer; an immunohistologic study emphasizing the different degrees of intestinal and gastric differentiation in signet ring cell carcinomas. Virchows Arch A Pathol Anat Histopathol 413: 303-312, 1988.

41. Robine S, Huet C, Moll R, Sahuquillo-Merino C, Coudrier E, Zweibaum A and Louvard D: Can villin be used to identify malignant and undifferentiated normal digestive epithelial cells? Proc Natl Acad Sci USA 82: 8488-8492, 1985.
42. Xieraili M, Yasen M, Mogushi K, Obulhasim G, Mayinuer A, Aihara A, Tanaka S, Mizushima H, Tanaka H and Arii S: Villin 1 is a predictive factor for the recurrence of high serum alpha-fetoprotein-associated hepatocellular carcinoma after hepatectomy. Cancer Sci 103: 1493-1501, 2012.

43. Pereira HA, Shafer WM, Pohl J, Martin LE and Spitznagel JK: CAP37, a human neutrophil-derived chemotactic factor with monocyte specific activity. J Clin Invest 85: 1468-1476, 1990.

44. Raff JW: Centrosomes and cancer: Lessons from a TACC. Trends Cell Biol 12: 222-225, 2002.

45. Mahoney JA, Ntolosi B, DaSilva RP, Gordon S and McKnight AJ: Cloning and characterization of CPVL, a novel serine carboxypeptidase, from human macrophages. Genomics 72: 243-251, 2001. 